Bahaya Minuman Keras untuk Remaja

\title{
PENYALAHGUNAAN KONSUMSI ALKOHOL PADA MINUMAN KERAS BAGI REMAJA TERHADAP KESEHATAN
}

\author{
Lela Tri Wahyu Liana; Leonardo Luciano Adolf \\ lelaliana514@gmail.com, ronaladolf75@gmail.com
}

STIKes Surya Mitra Husada

\begin{abstract}
Abstrak
Alkohol adalah kandungan yang ada pada minuman keras yang bila dikonsumsi secara terus menerus dan dalam jumlah yang tiap harinya semakin meningkat akan mengakibatkan dampak buruk bagi kesehatan baik jasmani maupun rohani. Terutama seseorang yang sudah kecanduan karena mengonsumsinya secara berkala. Sedangkan banyak remaja di era sekarang dengan pergaulan yang begitu mengerikan atau remaja yang masuk pergaulan yang salah menjadikan minuman keras sebagai trend yang malah menjadi suatu hal yang mereka banggakan, tanpa takut dampak dari minuman keras yang mengandung alkohol bisa menjadi masalah yang sangat mengkhawatirkan khusunya remaja yang sedang dalam fase dimana mereka merasa hal yang mereka lakukan semuanya benar. Karena kebanyakan di masyarakat minuman keras disalahgunakan apalagi mengonsumsinya dengan dosis atau takaran yang di luar batas yang bisa mengakibatkan seseorang mabuk dan kehilangan akal sehatnya.
\end{abstract}

\section{Kata Kunci: Alkohol, Minuman Keras, Remaja, Kesehatan}

\section{Latar Belakang}

Penyalahgunaan alkohol pada minuman keras di masyarakat bukan lagi kejadian yang pertama terjadi tetapi sudah menjadi masalah yang berkembang khususnya di kalangan remaja dan dari tahun ke tahun cenderung menunjukkan peningkatan. Penyalahgunaan minuman keras ini juga mengakibatkan beberapa bentuk masalah sosial seperti perkelahian, kenakalan remaja, tindakan asusila bahkan remaja yang kemudian semakin tidak memiliki norma dan cenderung sulit mengontrol emosinya.

Masa Remaja adalah masa peralihan dari masa anak-anak menuju dewasa. Di masa tersebut seseorang cenderung sulit dikontrol emosinya dan lebih suka bertindak semaunya sendiri. Masa itu juga disebut masa pencarian jati diri dimana seseorang akan memiliki rasa ingin tahu yang sangat tinggi dan mencoba hal baru yang dirasa cocok dengan kepribadiannya, kesukaannya atau mengidolakan 
sesuatu hal dari sudut pandangnya.

Tanpa berpikir lebih matang terlebih dahulu atas dampak apa yang bisa terjadi. Remaja cenderung sembrono. Maka dari itu pengawasan orang tua saat anak Hingga bisa memberikan dampak negatif entah itu dari segi jasmani atau rohani.

Minuman keras adalah segala jenis minuman memabukkan yang mengandung alkohol seperti wine, whiskey, brandy dan lain-lain yang jika diminum akan membuat seseorang yang meminumnya akan kehilangan kesadaran atau akal sehatnya. Sebenarnya alkohol itu sendiri tidak selamanya mengakibatkan dampak buruk, karena alkohol juga bisa menjadi pelarut yang paling bermanfaat dalam dunia farmasi. Yang menyebabkan alkohol menjadi sebuah hal yang menakutkan adalah ketika seseorang menyalahgunakannya contohnya seseorang yang min minuman keras beralkohol dengan sembrono atau meminumnya secara berlebihan dengan iming-iming bisa sejenak menghilangkan penat karena kesadaran yang akan hilang untuk sesaat salama orang tersebut dibawah pengaruh alkohol. Selain itu penyalahgunaan bisa berupa

\section{Kasus/ Masalah}

Tasikmalaya - Tiga pelajar di Tasikmalaya diduga over dosis minuman keras (miras) oplosan. Dua orang kritis di rumah sakit, satu lainnya tewas selagi mendapatkan perawatan medis. berada pada fase remaja sungguh sangat diperlukan, orang tua harus memberikan perhatian lebih dan bimbingan atau arahan, agar anak tidak salah masuk pergaulan.

mengoplos minuman keras dengan bahan-bahan yang berbahaya. Hingga mereka menyebutnya miras oplosan yang murah untuk mereka tapi membawa segudang bahaya kesehatan entah rohani maupun jasmani.

Sebagian besar korban penyalahgunaan alkohol adalah remaja. Hal ini berarti bahwa remaja merupakan sumber daya manusia yang potensial menjadi tidak dapat berfungsi secara maksimal akibat semakin luasnya penyalahgunaan narkoba dan minuman keras.

Dampak kesehatan dari minuman keras beralkohol yang salah digunakan bisa berakibat berbahaya seperti penyakit kerusakan otak, depresi, jantung, kanker, masalah paru, gangguan hati, perut dan sistem pencernaan serta keracunan alkohol yang tidak bisa dianggap sepele begitu saja.

Tiga remaja lelaki itu masingmasing inisial ADM (16), A (17) dan W (18). Satu pelajar yang nyawanya tak tertolong ialah A. 
Satu remaja kritis, ADM, warga Ciamis, Jawa Barat, diboyong keluarganya ke RS Jasa Kartini, Kota Tasikmalaya. Keluarga menduga ADM over dosis usai menenggak miras oplosan. Selain muntah, ADM mengalami kejang hebat hingga tak sadarkan diri.

"Keponakan saya masuk rumah sakit ini sudah kritis. Dugaannya dia minum miras oplosan sama dua temanya. Jadi total tiga orang," ucap Toni Apriantono, paman ADM, di RS Jasa Kartini, Sabtu (15/9/2018).

Berdasarkan keterangan keluarga, ADM menggelar pesta miras bersama A dan $\mathrm{W}$ di kawasan Leuwidahu, Tasikmalaya, Jumat (14/9) kemarin. Tragisnya, A meninggal dunia, Jumat malam. Nyawa warga Kota Tasikmalaya tersebut tak bisa diselamatkan

\section{Metode}

Metode penelitian yang digunakan dalam penelitian ini adalah metode penelitian kuantitatif deskriptif yaitu dengan cara mencari informasi tentang gejala yang ada,

\section{Pembahasan}

\section{a. Pengertian}

Minuman beralkohol adalah minuman yang mengandung etanol. Etanol adalah bahan psikoaktif dan konsumsinya menyebabkan penurunan kesadaran. Di berbagai negara, penjualan minuman beralkohol dibatasi ke sejumlah kalangan saja, umumnya orang-orang meski sempat menjalani tindakan medis

"Satu temanya meninggal Jumat malam jam tujuh, Keponakan saya sekarang dibantu alat," ucap Toni.

Peristiwa ini terjadi di luar jam pelajaran sekolah karena ketiganya libur. ADM selama ini tinggal di asrama sekolah, namun saat kejadian maut itu dijemput salah satu temannya.

"Keponakan saya lagi libur sekolah. Di sekolah itu sebetulnya menginap kayak pesantren, cuma karena libur dijemput W," ujar Toni.

Sedangkan kondisi W masih mendapat pertolongan medis. Belum diketahui pasti jenis miras yang ditenggak korban. Keluarga berencana melaporkan kejadian tersebut ke polisi.

didefinisikan dengan jelas tujuan yang akan dicapai, merencanakan cara pendekatannya, mengumpulkan data sebagai bahan untuk membuat laporan.

yang telah melewati batas usia tertentu. (Zulvikar, 2008)

Dalam ilmu kimia, alkohol adalah istilah yang umum bagi senyawa organik apapun yang memiliki gugus hidroksil (-OH) yang terikat pada atom karbon, yang ia sendiri terikat pada atom hidrogen dan atau atom karbon 
lain. Dilihat dari gugus fungsinya, alkohol memiliki banyak golongan. Golongan yang paling sederhana adalah metanol dan etanol.

Sementara John Wiley dan Soon dalam bukunya Introduction to Organic Chemistry menjelaskan bahwa: "Alkohol adalah senyawa organic yang memiliki gugus hidroksil (-OH) yang terikat pada atom karbon, yang b. Penggunaan Alkohol

Alkohol yang sering digunakan sebagai pelarut adalah jenis metanol, etanol dan isopropanol. Metanol digunakan sebagai pelarut dalam cat, bahan anti beku dan senyawa kimia lainnya. Sedangkan etanol

\section{c. Pengaturan dan Kandungan minuman keras}

Pengaturan minuman beralkohol yang pada umunnya disebut sebagai minuman keras, terdapat dalam peraturan Menteri Kesehatan tentang minuman

keras Nomor

86/Men/Kes/Per/IV/77.

Di dalam peraturan tersebut, minuman keras digolongkan sebagai berikut:

Golongan A : Kadar Etanol 1$5 \%$

Golongan B : Kadar etanol 5$20 \%$

Golongan C : Kadar etanol 2055\% (Sasangka, 2003)

\section{d. Bahaya Alkohol}

Selama ini, stigma yang berkembang di masyarakat adalah alkohol dapat merusak tubuh. Agaknya, pandangan seperti ini perlu diluruskan. ia sendiri terikat pada atom hidrogen dan atau atom karbon lain. Dengan mensubstitusikan $\mathrm{OH}$ ke $\mathrm{H}$ dari $\mathrm{CH} 4$, maka didapat $\mathrm{CH} 3 \mathrm{OH}$ yang dikenal methanol. Rumus fungsional dari alkohol adalah $\mathrm{OH}$ dengan formula umum untuk alkohol $\mathrm{ROH}$, dimana $\mathrm{R}$ adalah alkil atau substitusi kelompok alkil" (John and Soon, 2011)

banyak digunakan sebagai pelarut, antiseptic, campuran obat batuk, anggur obat, bahan minuman keras dan minuman lain yang mengandung alkohol. (Koes, 2013)

Di bawah ini contoh-contoh minuman keras dengan kadar kandungannya.

- Anggur : mengandung 10-15\%

- Bir : mengandung 2-6\%

- Brandy (Bredewijn) : mengandung $45 \%$

- Rum : mengandung 50-60 \%

- Likeur : mengandung 35- $40 \%$

- Sherry/Port : mengandung 15$20 \%$

- Wine (anggur) : mengandung $10-15 \%$

- Wisky (Jenewer) : mengandung 35-40\%

(Sasangka, 2003).

Pasalnya, pada dosis yang rendah (tidak memabukkan), alkohol justru menguntungkan bagi tubuh. Beberapa hasil studi melaporkan studi menyatakan 
bahwa konsumsi alkohol mampu menurunkan serangan jantung, stroke, dan mencegah kemungkinan munculnya serangan Alzheimer. (Muchlis and Dito, 2018)

Kendati alkohol dalam dosis yang rendah bermanfaat bagi tubuh, namun alkohol juga bersifat racun. Ada dua jenis alkohol yang bersifat racun yaitu etil alkohol atau etanol dan metil alkohol atau metanol. Etil alkohol terdapat dalam minuman alkohol dan obat yang diolah (larutan alkohol), keracunan ini ditandai dengan mabuk, perubahan emosi yang mendadak, mual, muntah, tidak sadarkan diri bahkan meninggal akibat lumpuhnya alat pernapasan. Metil alkohol biasanya digunakan sebagai campuran cat, bahan pengencer, penghancur, dan pemberi panas pada makanan yang dikalengkan. Gejala yang ditimbulkan pada keracunan alkohol metil hampir sama dengan keracunan etil alkohol.

Faktor yang Mempengaruhi

e. Faktor yang Mempengaruh
Puspitawati (2004)

menyebutkan beberapa remaja

terjerumus dalam masalah

minuman keras karena

dipengaruhi lingkungan

pergaulan antara lain sebagai

berikut :

- Remaja yang selalu minum-minuman keras selalu mempunyai "kelompok pemakai". Awalnya remaja hanya mencoba-coba karena
Hanya saja penderita biasanya mengalami kebutaan akibat adanya pengrusakan saraf mata.

Seseorang pecandu minuman keras dimulai dengan meminumminuman lebih banyak dari yang lain, yang akhirnya menyebabkan hang over (perasaan sakit esok harinya setelah minum terlalu banyak). Hal tersebut bisa disembuhkan dengan minum lagi sehingga tidak bisa pisah dari minuman keras.

Pada umumnya, konsumsi alkohol merusak semua organ tubuh secara berangsur-angsur akibat penggunaannya, dapat menyebabkan peradangan hati (liver chirrhosis), menyebabkan pendarahan dalam perut (mag), penyakit jantung (cardiomyopathy), hormon seks, dan sistem kekebalan tubuh. Pengaruhnya terhadap otak dapat secara akut (intoksisasi, delirium) atau kronis (ataxia, pelupa, koordinasi motorik). (Aliah, 2008)

\section{i Penggunaan Alkohol pada Remaja}


dengan teman-teman sebanyanya.

- Adanya "ajakan" atau "tawaran" dari teman serta banyaknya film dan sarana hiburan yang memberikan contoh "model pergaulan moderen" biasanya mendorong remaja minum-minuman keras secara berkelompok.

- Apabila remaja telah menjadi terbiasa minum minuman keras dan karena mudah mendapatkannya, maka remaja akan memakainya sendiri sehingga tanpa disadari lama-kelamaan akan ketagihan.

Penggunaan minuman keras di kalangan remaja umumnya karena minuman keras tersebut menjanjikan sesuatu yang menjadi rasa kenikmatan, kenyamanan dan kesenangan dan ketenangan walaupun hal itu dirasakan secara semu.

\section{f. Ciri-ciri Perilaku Remaja yang Mengonsumsi minuman keras}

Menurut Puspitawati (2004) diantaranya adalah:

- Perubahan perangai atau perilaku seperti : yang biasanya periang tibatiba menjadi pemurung, mudah tersinggung dan cepat marah tanpa alasan yang jelas.

- Sering menguap dan menhantuk, malas, melamun dan tidak memperdulikan

kebersihan dan
penampilan diri.

- Menjadi tidak disiplin, atau sering kabur, baik di rumah maupun di sekolah.

- Nilai rapor atau prestasinya menurun.

- Bersembunyi di tempat gelap atau sepi agar tidak terlihat orang.

- Lebih banyak bergaul dengan orang-orang tertentu saja yang mempunyai

ciri-ciri dan tanda-tanda diatas.

- Mencuri apa saja milik orang tua atau saudara untuk membeli minuman keras.

- Sering cemas, mudah stress atau gelisah, sukar tidur.

- Pelupa, seperti orang bego atau pikun.

- Mata merah seperti mengantuk terus atau memakai kacamata hitam 


\section{g. Dampak dari Penggunaan Minuman Keras Beralkohol}

- Gangguan Kesehatan

Fisik

Djajosman

menyatakan, meminum

minuman keras dalam

jumlah yang banyak dan dalam waktu yang lama menimbulkan kerusakan dalam hati, jantung pankreas, lambung dan otot. Pada pemakaian kronis minuman keras dapat terjadi pergeseran hati, peradangan pangkreas dan peradangan lambung.

Lemak di Liver dimana tugas hati atau liver adalah memetabolisme nutrisi dari makanan atau minuman yang dikonsumsi. Terlalu banyak minum alkohol membebani hati.

"Kelebihan lemak disimpan dalam sel-sel hati. Mereka terakumulasi untuk membentuk hati yang berlemak," kata Robert

- Gangguan Kesehatan Jiwa Meminum minuman keras secara kronis dalam jumlah berlebihan dapat menimbulkan kerusakan jaringan otak sehingga menimbulkan gangguan daya ingatan, kemampuan penilaian, kemapuan belajar, dan gangguan jiwa tertentu. Akibat minuman keras,
Duhaney, MD, seorang internis di Amerika Serikat.

Semua lemak berlebih ini, meningkatkan risiko terkena hepatitis alkohol. Selain itu, bisa menyebabkan sirosis dan membuat hati tidak bisa melakukan fungsinya.

Stroke dimana sekalipun hati Anda sehat, konsumsi alkohol berlebih tetap bisa menyebabkan stroke. Sebuah studi menemukan, pria yang mengonsumsi lebih dari 6 kali dalam sehari, atau wanita yang minum lebih dari 4 kali, memiliki risiko stroke hampir 40 persen lebih tinggi, dibanding mereka yang tidak pernah minum alkohol. Hal ini juga terkait tekanan darah tinggi yang merupakan faktor risiko stroke.

alam perasan seseorang menjadi berubah,

orang menjadi mudah tersinggung dan perhatian terhadap lingkungan terganggu yang pada giliranya tersingkirkan dari lingkungan sosialnya dan atau dikeluarkan dari pekerjaannya. 


Menenggak minuman
beralkohol hanya akan
membuat perasaan lebih
baik di awal saja.
Namun, tubuh akan
memecah zat kimia yang
ada dalam alkohol. Hal
ini membuat kestabilan
neurontransmiter dalam
otak terganggu.
Menurut National
Institute on Alcohol
Abuse and Alcoholism
(NIAAA), dalam jangka
pendek alkohol
memberikan penurunan
suasana hati. Seiring
waktu, hal itu
menyebabkan sel-sel

\section{Kesimpulan}

Penyalahgunaan dalam hal konsumsi minuman keras berkalkohol tidak bisa dipandang sebelah mata karena dampak yang diakibatkan tidak main-main. Apalagi karena penyalahgunaan terkait miras oplosan yang sedang banyak terjadi di masyarakat bisa membuat seseorang sampai tewas. Sebab bahan yang digunakan dalam mengoplos minuman mudah didapatkan seperti alkohol sebagai bahan utama. Terlebih angka presentase korban dari penyalahgunaan alkohol tertinggi menyerang remaja.

Sungguh tragis memang bila melihat dan mendengar para remaja yang dianggap sebagai agen perubahan, harus mengenal dan menyalahgunakan minuman otak menyusut dan memicu masalah seperti depresi.

Kacaunya otak juga bisa membuat Anda kehilangan ingatan jangka pendek, serta masalah kognitif jangka panjang, termasuk demensia.

Sebuah penelitian di Perancis menemukan, dari 1 juta lebih orang dewasa yang mengalami kasus demensia, 57 ribunya terkait dengan konsumsi alkohol yang berlebihan. keras. Padahal pada kenyataannya perilaku remaja pengguna minuman keras ini merupakan sebagai bentuk kegiatan yang menyimpang dari moral, melanggar norma-norma sosial dan norma-norma agama. Jika kita terus membiarkannya, maka bukan tidak mungkin jika kita sama saja membunuh asset negara berupa generasi muda yang tambah hari tambah bobrok, sebab penyalahgunaan alkohol bisa menyebababkan depresi atau stress juga apalagi jika orang tersebut sudah kecanduan. Bimbingan dan perhatian dari orang tua sungguh saat diperlukan sebagai salah satu usaha preventif saat anak masuk fase remaja agar tidak salah masuk pergaulan. 


\section{DAFTAR PUSTAKA}

Zulvikar, 2008, Minuman-Minuman Keras ,http://zulv1ck4r.wordpress.com /2008/12/30/minum-minuman-keras/.

Sitasi 24 mey 2012

John Wiley dan Soon, Introduction To Organic Chemistry, (ttp.: t.p., 2011), hlm 487

Koes Irianto, Pencegahan dan Penanggulangan Keracunan Bahan Kimia Berbahaya, (Bandung: Yrama Widya, 2013), hlm. 98.

Muchlis Achsan Udji Sofro dan Dito Anurogo, 5 Menit Memahami 55 Problematika Kesehatan, (Yogyakarta: DMedika, 2013), hlm. 20

Aliah B. Purwakania Hasan, Pengantar Psikologi Kesehatan Islam, (Depok: PT RajaGrafindo Persada, 2008) hlm. 233.

Puspitawati, herein: Narkoba dan Minuman Keras ,http://www.hayati.Ipb.Com/user/rudyct/P ps 702/Herien.htm(22 Juni 2004)

Djajoesman, Noegroho. 1999. Mari Bersatu Memberantas Bahaya Penyalahgunaan Narkoba, Jakarta: Kepolisian Negara Republik Indonesia 